\title{
Electroporation-induced changes in normal immature rat myoblasts (H9C2)
}

\author{
Iwona Kaminska ${ }^{1,2}$, Malgorzata Kotulska², Anna Stecka², Jolanta Saczko ${ }^{1}$, Malgorzata Drag- \\ Zalesinska ${ }^{3}$, Teresa Wysocka ${ }^{3}$, Anna Choromanska ${ }^{1}$, Nina Skolucka ${ }^{1}$, Rafał Nowicki ${ }^{4}$, Jakub \\ Marczak $^{4}$ and Julita Kulbacka ${ }^{1}$ \\ ${ }^{1}$ Department of Medical Biochemistry, Wroclaw Medical University, Chalubinskiego 10, 50-367 Wroclaw, Poland \\ ${ }^{2}$ Institute of Biomedical Engineering and Instrumentation, Faculty of Fundamental Problems of Technology, Wroclaw University of \\ Technology, Wybrzeze Wyspianskiego 27, Wroclaw, Poland \\ ${ }^{3}$ Department of Histology and Embryology, Wroclaw Medical University, Chalubinskiego 6, 50-368 Wroclaw, Poland \\ ${ }^{4}$ Department of Cardiac Surgery, Medical University, Borowska 213, 50-556 Wroclaw, Poland
}

\begin{abstract}
Application of a high electric field causes an electric shock to the heart. This is utilized in defibrillation to reestablish normal contraction rhythms during dangerous arrhythmias or in cardiac arrest. If shock-induced transmembrane potentials are large enough, they can cause tissue destruction due to irreversible electroporation (EP). Also electrochemotherapy of nearby tissues may have an adverse effect on the heart. Herein, we present experimental data on effects of electroporation in culture of cardiac cells (H9C2). The electric field was applied in short pulses of 25-3250 V/cm, $50 \mu$ s each. The viability of cells was tested by MTT assay after 24 hours. For detection of DNA fragmentation, associated with apoptosis, alkaline and neutral comet assays were performed after EP. Additionally phase contrast images of cells obtained directly after EP were analyzed. Although cell images indicated disruption of cell membranes after EP with high intensities, only a few percent of apoptotic cells and no necrotic effects in the cell nucleus could be observed in comet assay tests performed 2 hours post EP. MTT viability test showed that pulse intensities above $375 \mathrm{~V} / \mathrm{cm}$ are destructive for myocytes viability.
\end{abstract}

Key words: Electroporation — Myoblasts - Comet assay

Abbreviations: ACA, alkaline comet assay; EP, elektroporation; NCA, neutral comet assay; PEA, pulseless electrical activity.

\section{Introduction}

High-intensity electric shocks are normally applied in medicine, especially to terminate atrial or ventricular fibrillation. During this process a phenomenon called electroporation (Neumann and Rosenheck 1972) is involved, inducing pores in cellular membranes (Nikolski and Efimov 2005; Dosdall et al. 2010). Electroporation (EP) has been widely used in the experiments of foreign gene transfection into cells (e.g.

Correspondence to: Julita Kulbacka, Department of Medical Biochemistry, Wroclaw Medical University, Chalubinskiego 10, 50-367 Wroclaw, Poland

E-mail: julita.kulbacka@am.wroc.pl
Neumann et al. 1982; Daud et al. 2008; Mir 2009) and in electrochemotherapy (Marty et al. 2006). On the other hand, high electric field can induce transient or permanent electrical effects on functioning of the heart muscle cells (Cheng et al. 1999; Fedoro et al. 2008; Dyachok et al. 2010; Klauke et al. 2010). Clinically, electrotherapy to the heart carries a high-risk of myocardial stunning which may produce pulseless electrical activity (PEA) or ventricular arrhythmias, therefore can be life-threatening to a patient (Deakin and Ambler 2006). Although mechanisms underlying high intensity shocks are used routinely (e.g. defibrillation) they still need clarification and better understanding.

Prerogatives of electric cardioversion and defibrillation are well appreciated both in acute and chronic heart failure 
(Deakin and Nolan 2005; Zareba et al. 2011). In ventricular dysrrhythmias prompt high-energy monophasic or biphasic electric shock can restore sinus rhythm and cardiac output (Deakin and Nolan 2005). Such modes of therapy have little or no contraindications bearing in mind the acute patient condition. There was commonly recognized that electrical manipulations performed on the heart induce heart attack risk, and therefore may be dangerous to the patient's life (Deakin and Ambler 2006). A novel cancer therapy, applied in the heart adjacent tissues, which uses high energy electric field, has a potential of inducing electroporation and subsequent damage to the heart (Neumann and Rosenheck 1972; de Oliveira et al. 2008, Deodhar et al. 2011). This deteriorative potential depends on the electrotherapeutical characteristics (intensity, frequency, shape and duration of an electrical pulse), distance of electric source from the heart and trans-thoracic impedance. In excellent designed study, Deodhar et al. observed that irreversible EP carries detrimental effect (ventricular arrhythmias) in vivo when electrical pulses are not applied synchronically with the $\mathrm{R}$ waves or the electrode is closer to the heart than 17 $\mathrm{mm}$ (Deodhar et al. 2011). Contrary to this finding Mali et al. (2008) have proven that to certain extent EP can be safely administered during electrochemotherapy of the chest malignancies. The only question that has not been addressed by any of these studies is the genuine impact of trans-thoracic impedance on the procedural safety of electrochemotherapy. As it has been shown in the defibrillation studies, trans-thoracic impedance can change in accordance to respiratory phase, body weight and individual changes of body constitution (musculature, female breast anatomy) thus providing the heart muscle with different electrical energy at a certain moment (Deakin and Nolan 2005). Therefore, electrochemotherapy safety assessment on strictly in vivo basis must be warranted in order to provide the complex experimental model embodying all above mentioned features.

There are two hypotheses concerning the relationship between electroporation and defibrillation (Nikolski and Efimov 2005). Incapacitation theory places electroporation as mechanisms basis for defibrillation. There are theoretical (Roth and Krassowska 1998) and experimental (Nikolski and Efimov 2005) studies supporting the hypothesis that only electropores enable distribution of electric shocks throughout an extensive area of cardiac tissue and terminate spiral waves characteristic of a heart arrhythmia. Stimulation theory ignores the role of electroporation in defibrillation. On the other hand, typical electrochemotherapy does not pose a significant danger for heart functioning, as shown in vivo (Mali et al. 2008), but if electrodes are located close to the heart, certain effects on myocytes might become inevitable. Further studies on EP may show mechanisms of cellular response to high electric fields applied to cardiac cells, which can contribute to the reduction of side effects involved in defibrillation therapy and electrochemotherapy in the chest.

The main objective of our study was the observation of changes induced by electroporation in neonatal rat myoblasts (H9C2), also in very high electric fields, and their development in time. Myoblasts were treated here as a heart model exposed to EP. We attempted to determine the pulse intensity threshold discriminating between safe conditions and massive myocytes destruction. Electroporation parameters (intensity, frequency, shape, and duration), which are typically used in electrochemotherapy, resembled our protocol. The only difference could have been in the pulse duration, which is more typically twice longer in electrochemotherapy, hence, the higher total energy in that case. The study was accompanied by comet assays showing phenomena in cell nuclei shortly after application of electroporation, with parameters resembling those used in electrochemotherapy. The comet assay is a relatively uncomplicated technique that allows determining not only the percentage of apoptotic nuclei, but also the level of genotoxic damage induced by an apoptotic trigger (Nelms et al. 1997). The myocytes were simultaneously observed in a light microscope.

\section{Materials and Methods}

\section{Cell culture}

The study was carried out on normal myoblast cells H9C2 (from neonatal rat heart). The cells were cultured in Dulbecco Modified Eagle Medium (DMEM, Lonza) with 10\% fetal bovine serum (FBS, BioWhittaker) and L-glutamine with penicillin and streptomycin (Sigma). They were maintained in a humidified atmosphere at $37^{\circ} \mathrm{C}$ in $5 \% \mathrm{CO}_{2}$. Cells before experiments were separated from the substrate by using trypsin solution ( $0.25 \%$ Trypsin - EDTA, Sigma), which was then neutralized in serum contained in the medium.

\section{Electroporation (EP)}

EP was performed with ECM 830 (BTX) square-wave electroporator in electroporation cuvettes with two thin aluminum parallel electrodes, $4 \mathrm{~mm}$ apart (Cuvettes Plus 640, $800 \mu \mathrm{l})$. Cells in suspension were centrifuged for $5 \mathrm{~min}$ at $1500 \mathrm{rpm}$ and resuspended in the electroporation buffer with low electrical conductivity ( $10 \mathrm{mM}$ phosphate, $1 \mathrm{mM} \mathrm{MgCl}_{2}$, $250 \mathrm{mM}$ sucrose, $\mathrm{pH}$ 7.4). Cells were used for experiments after 20 min post electroporation to establish cell membrane conditions (so-called "releasing time") and then resuspended in DMEM. The EP parameters were: $25-3250 \mathrm{~V} / \mathrm{cm}, 50 \mu \mathrm{s}$, 5 impulses in a cycle of frequency $1 \mathrm{~Hz}$. 


\section{Light microscopy}

H9C2 cells before and after electroporation at $500 \mathrm{~V} / \mathrm{cm}$, 5 pulses of $50 \mu$ s each, were placed on a basic slide in $20 \mu \mathrm{l}$ of DMEM. Cells were observed using upright microscope Nikon Eclipse TS100F.

\section{Alkaline comet assay (ACA)}

For detection of DNA fragmentation associated with apoptosis, alkaline comet assay method described by Ashby (1995) was used. H9C2 cells were treated by EP at the selected electric field intensities and 2 hours after EP subjected to ACA procedure. Cells after EP remained in cell culture medium. The cells, at the concentration of $1 \times 10^{5} / \mathrm{ml}$, were mixed with low temperature melting agarose (Sigma) at $1: 10$ $(\mathrm{v} / \mathrm{v})$ ratio and spreaded on a slide. Slides were submerged in precooled lysis solution $(1.2 \mathrm{M} \mathrm{NaCl}, 30 \mathrm{mM} \mathrm{NaOH}, 2 \mathrm{mM}$ EDTA, $1 \%$ Triton X-100) at $4^{\circ} \mathrm{C}$ for $60 \mathrm{~min}$. After lysis and rinsing, slides were equilibrated in TBE solution $(40 \mathrm{mM}$ Tris/boric acid, $2 \mathrm{mM}$ EDTA, $\mathrm{pH} 8.3$ ), electrophoresed at $1.0 \mathrm{~V} / \mathrm{cm}^{2}$ for $20 \mathrm{~min}$ and then silver staining was performed. For scoring the comet pattern, 100-200 nuclei from each slide were evaluated.

\section{Neutral comet assay (NCA)}

For detection of DNA fragmentation associated with apoptosis, NCA method described by Collins (2002) was used. All steps before the lysis procedure were performed similarly as those in the ACA. Then, the slides were placed in a cold lysis solution ( $146 \mathrm{mM} \mathrm{NaCl}, 30 \mathrm{mM}$ EDTA, $\mathrm{pH}$ 8, 1 mM Tris- $\mathrm{HCl}, \mathrm{pH} 8,0.1 \%$ N-lauroylsarcozine; $\mathrm{pH} 9)$ for $60 \mathrm{~min}$ and then washed in TBE solution $(40 \mathrm{mM}$ Tris/boric acid, 2 mM EDTA, pH 8.3). Next, the samples were electrophoresed at $1.0 \mathrm{~V} / \mathrm{cm}^{2}$ for $20 \mathrm{~min}$ and then silver staining was performed. To rank apoptotic comets, we followed the method developed by Collins (2002). For scoring the comet pattern, 100-200 nuclei from each slide were evaluated.

\section{Cells viability}

The cells viability was determined by MTT assay (3- $(4,5-$ dimethylthiazol-2-yl)-2,5-diphenyl tetrazolium bodmide, a yellow tetrazole; Sigma Chemical Co.; 71K8409, In Vitro Toxicology Assay) as mitochondria metabolic function. After EP cells were left for $20 \mathrm{~min}$ with addition of $1600 \mu \mathrm{l}$ DMEM, then washed and centrifuged twice with DMEM. Then cells were seeded into 96-well microculture plates and allowed to attach ( $24 \mathrm{~h})$. Next, they were treated according to the manufacturer's protocol. The absorbance was determined using the multiwell scanning spectrophotometer at $570 \mathrm{~nm}$ (Multiscan MS microplate reader). The function of mitochondria was expressed as a percentage of viable treated cells relative to untreated control cells.

\section{Statistical analysis}

The significance of the difference between mean values of different groups of cells was assessed by Student's $t$-test with $p$ value of $p \leq 0.05$, to show the statistical significance. Results were analyzed by the commercial software Statistica 9.0.

\section{Results}

Visual inspection of rat myoblasts presented in the Fig. 1, which underwent electroporation, show their high sensitivity to the electric field. Fig. 1 shows cells before (A) and after the
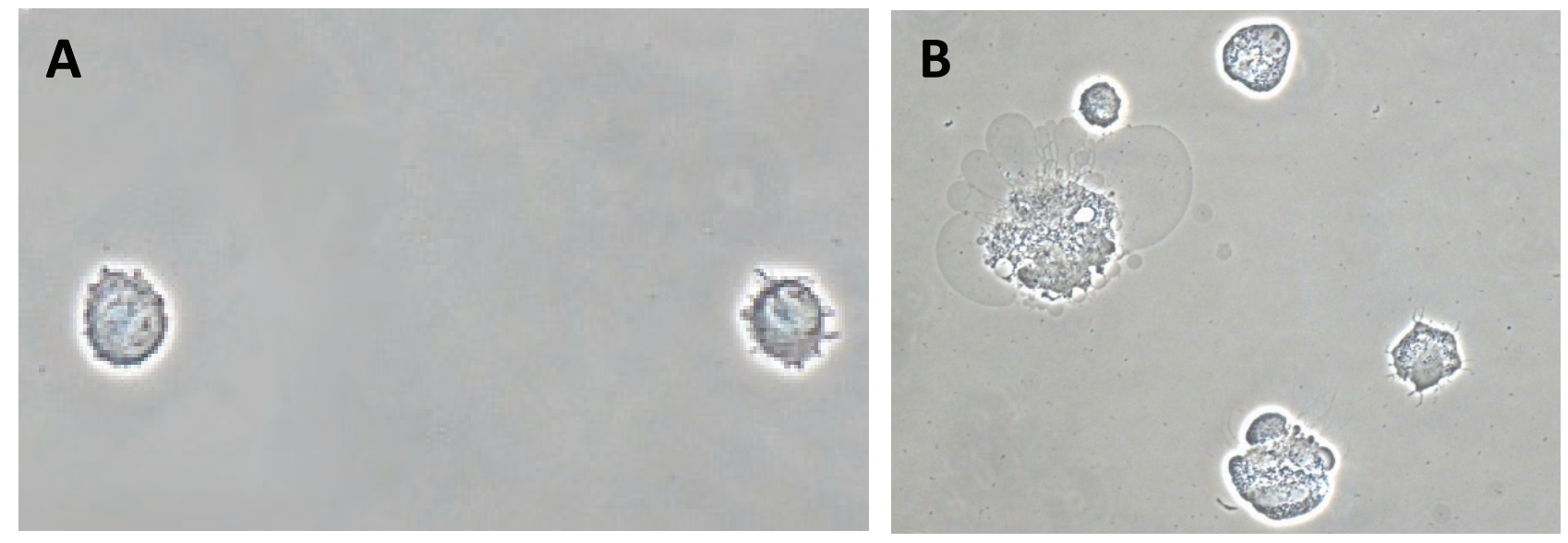

Figure 1. Morphology of H9C2 cells before electroporation $(\times 400$; A) and after electroporation on $500 \mathrm{~V} / \mathrm{cm}, 5 \mathrm{imp}$. and $50 \mu \mathrm{s}(\times 400$; B). 
- apoptosis no damage

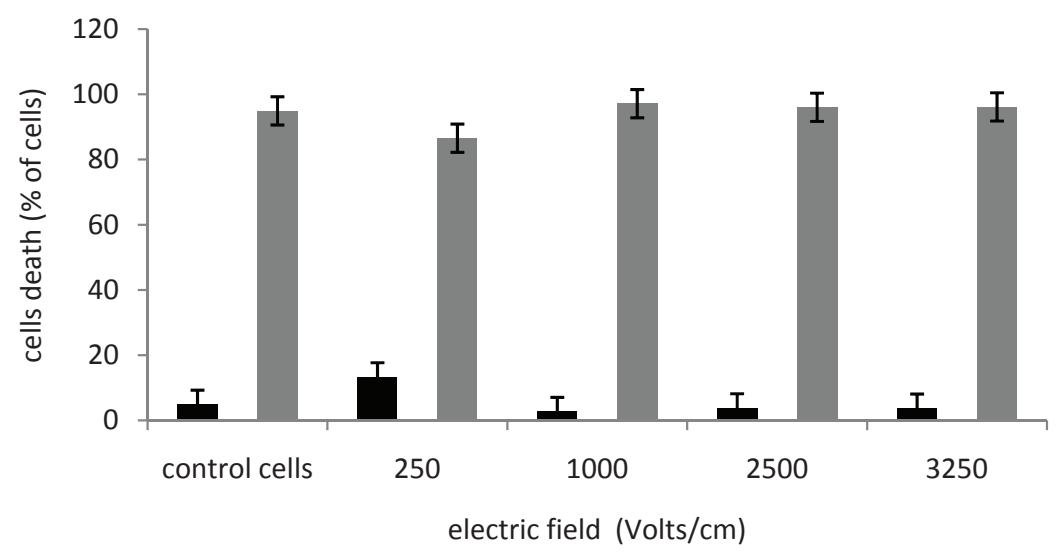

Figure 2. Neutral comet assay of rat myoblasts after electroporation ( $5 \mathrm{imp}$. and $50 \mu \mathrm{s}$ ). Error bars shown are means \pm SD for $n=3$.

electroporation (B) with electric field intensity of $500 \mathrm{~V} / \mathrm{cm}$. As it could have been observed, there were visible changes on the cell surface right after application of EP. Cells were swollen and "blebbing". In most cases these changes led to irreversible rupture of the cell membrane and subsequent cell death.

In Figures 2 and 3 comet assays results are presented. The results were obtained 2 hours post electroporation. The neutral variant (Fig. 2) is more sensitive than the alkaline method (Fig. 3). As it can be seen in NCA (Fig. 2), typically only $5 \%$ of cells underwent apoptosis and the rest of the cell nuclei were not damaged. Interestingly, the highest apoptosis level $(13.4 \%)$ was observed for the intensities close to the safety threshold (Fig. 4), which may indicate slightly elevated response of cells strongly affected by the electric field, not observed at higher and immensely destructive field levels.
The results from ACA (Fig. 3) showed that single cell nuclei underwent intermediate damage. Here, "intermediate damage" means that cells started to die but in this step we expect information if they undergo apoptosis or necrosis. Other cell nuclei were registered as not damaged.

The intensity threshold, in which cardiac myocytes are safe in terms of their viability, has also been tested. The viability was expressed as a mitochondrial activity of cells 24 hours post EP. The results of MTT, relative to the control cells that underwent the same procedures but excluding $\mathrm{EP}$, are presented in Fig. 4. In the figure results statistically significant are taken in the buckle and marked by asterisks. The results show that after pulses below $300 \mathrm{~V} / \mathrm{cm}$, cells can be considered as relatively safe in terms of their viability and proliferation since mitochondrial activity was higher than $50 \%$ of control cells. Only after application of electrical field

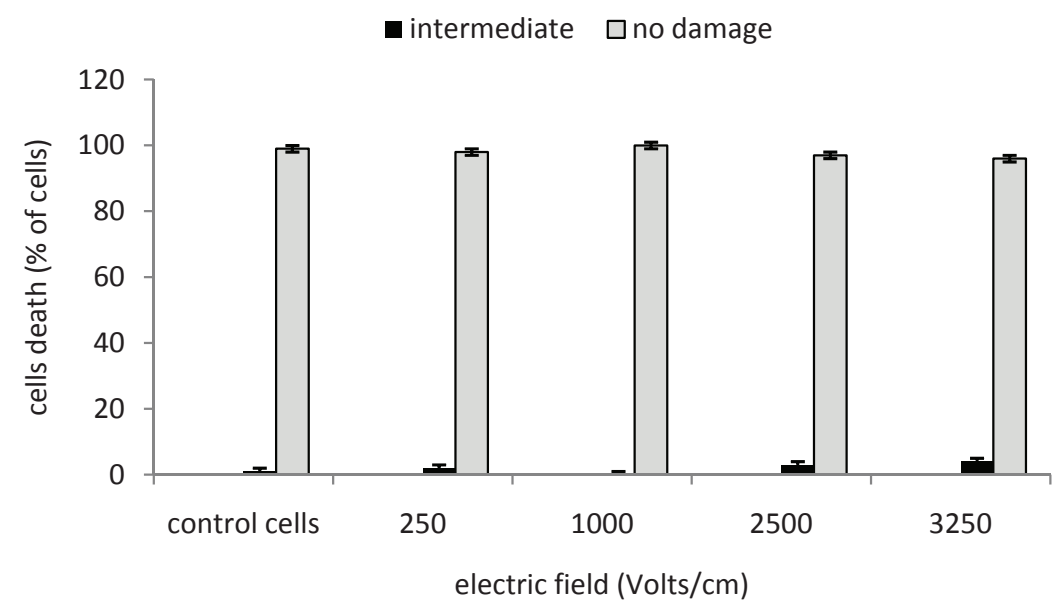

Figure 3. Alkaline comet assay rat myoblasts after electroporation ( $5 \mathrm{imp}$. and $50 \mu \mathrm{s})$. Error bars shown are means $\pm \mathrm{SD}$ for $n=3$. 


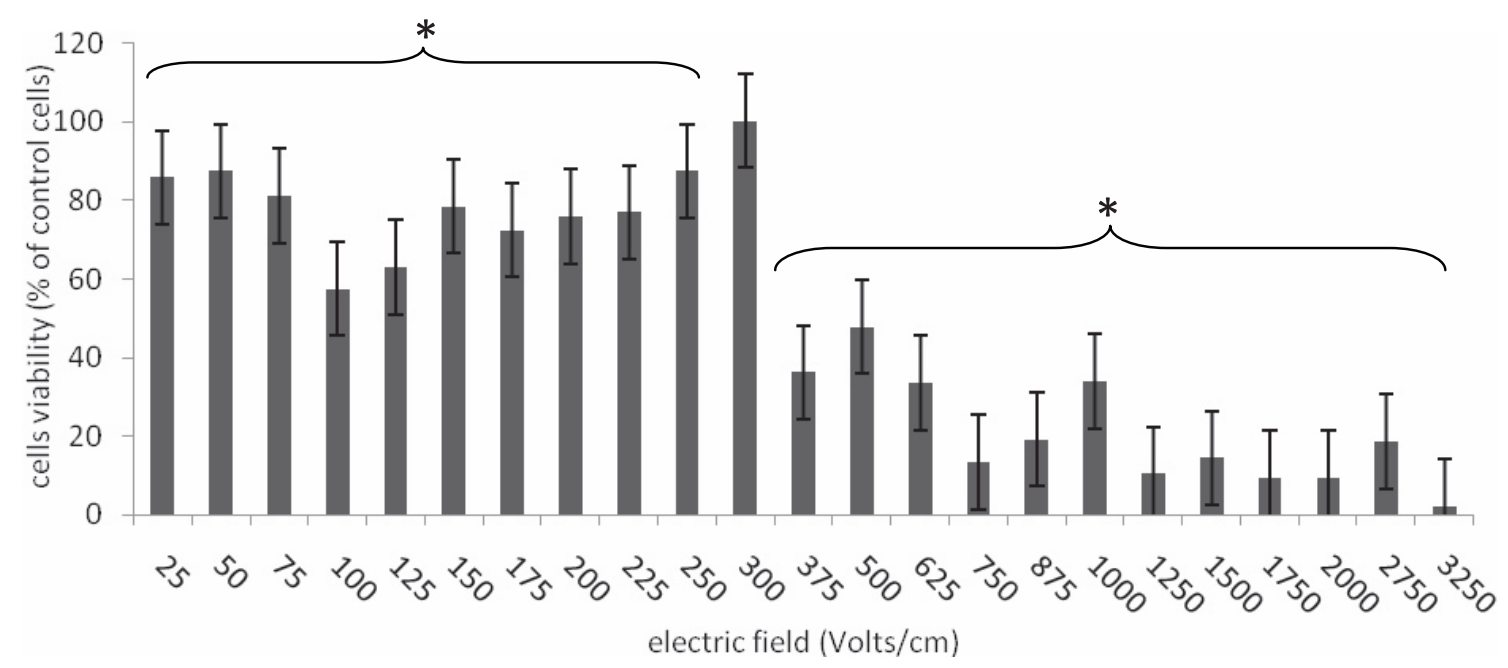

Figure 4. The viability test in rat myoblasts after electroporation ( $5 \mathrm{imp}$. and $50 \mu \mathrm{s}$ ). Error bars shown are means $\pm \mathrm{SD}$ for $n=4 .{ }^{*}$ results statistically significant for $p \leq 0.05$.

of $375 \mathrm{~V} / \mathrm{cm}$ and above, cells proliferation decreased below $40 \%$, and for $3250 \mathrm{~V} / \mathrm{cm}$ fell to $2 \%$. The results from MTT showed a general condition of electroporated cells in the culture after 24 hours. It complements the comet assay that showed what was an immediate effect of electroporation on the cell nucleus, 2 hours post EP.

\section{Discussion}

The study assessed sensitivity of rat cardiomyocytes to the electroporation. It enables for the analysis of cellular mechanisms involved during the application of low and high-intensity shocks and lethal effects following electroporation. Hescheler et al. (1991) have demonstrated that H9C2 cells possess certain membrane surface and electrochemical characteristics of cardiomyocytes. These cells have dedifferentiated to a high degree. The authors identified that H9C2 cells show morphological characteristics similar to those of immature embryonic cardiocytes but preserved several elements of the electrical and hormonal signal pathway, which can be found in the adult cardiac cells. Hescheler et al. (1991) suggested that this cell line may be useful as a model for cardiocytes in aspects of transmembrane signal transduction. As expected, immature cardiomyocytes show significantly lower viability threshold value of the pulse intensities than cells of other tissues treated by the same protocol (e.g. Saczko et al. 2010; Skolucka et al. 2011). The effect of EP above this pulse intensity can also be observed on phase contrast images of cells, obtained directly after EP. Cells are swollen and plasma membranes disintegrated in some cells. The event, observed as membrane blebbing, can be detected during the execution phase of apoptosis. In their study, Coleman et al. (2001) presented electron micrographs of blebbing of NIH 3 T3 cells. Also inside the cells, morphological changes take place. This was observed in our previous study under electron microscopy for normal and malignant cells after EP of intensities moderately safe for their viability (Skolucka et al. 2011). Although myocytes are very easily affected by the electric field, their nuclei do not show a very strong and immediate response, as indicated by comet assays. After 2 hours of EP, a few percent of cells undergo apoptosis, while the rest of the cell nuclei do not show any response. Interestingly, the highest apoptosis level was observed for EP intensities near cellular viability threshold. We hypothesize, that this slightly elevated response of cells is strongly affected by the electric field and indicates their attempt to control their disintegration process. In very strong fields above cell viability threshold, the apoptotic response is impeded.

Other authors, studying the effects of defibrillating electric fields, presented detrimental influence of electroporation at lower pulse intensities than in our study. De Oliviera et al. (2008) applied electroporation on ventricular adult rat myocytes, using pulses at the frequency of 0.5 $\mathrm{Hz}$, significantly longer $(10 \mathrm{~ms})$ than in our study. Their results show that $\mathrm{E} \sim 80 \mathrm{~V} / \mathrm{cm}$ is lethal to over $75 \%$ of the cell population when applied longitudinally to the cell major axis, but to less than $3 \%$ of the cells when stimulus orientation is transversal. The viability of $50 \%$ was achieved at $50 \mathrm{~V} / \mathrm{cm}$ for longitudinal and $125 \mathrm{~V} / \mathrm{cm}$ at transversal orientations of single myocytes. Their results show that $\mathrm{E}>$ $50 \mathrm{~V} / \mathrm{cm}$, which may be achieved in certain regions of the myocardium during clinical defibrillation, causes irreversible damage to cardiomyocytes (de Oliviera et al. 2008). In 
elegantly designed study, Deodhar et al. (2001) observed that irreversible EP carries detrimental effect (ventricular arrhythmias) in vivo when electrical pulses are not applied synchronically with the $\mathrm{R}$ waves or the electrode is closer to the heart than $1.7 \mathrm{~cm}$. However, results of de Oliveira and Deodhar are not compatible with the electrochemotherapy conditions. It was only the in vivo study by Mali et al. (2008), who examined the effects of short $(100 \mu \mathrm{s}) \mathrm{EP}$ pulses on functioning of the heart. The authors measured ECG signals during electrochemotherapy and analyzed their characteristics. They found no arrhythmias or other pathological morphological changes due to application of EP pulses. The only demonstrated effect of EP pulses on ECG was a transient RR interval decrease.

The presented results allow for a better insight into the cellular phenomena in cardiac tissue during defibrillation and during electrochemotherapy in the chest. This may contribute to select appropriate EP parameters and minimize the adverse effects on cardiac muscle.

Acknowledgments. This study was supported by statutory funds of Medical Wroclaw University and research fellowship within "Development program of Wroclaw Medical University" funded from European Social Fund, Human Capital, and National Cohesion Strategy" (No. UDAPOKL. 04.01.01-00-010/08-00). IK and AS were also in part supported by students scientific association "Bio-Nanopore" at Wroclaw University of Technology.

\section{References}

Ashby J., Tinwell H., Lefevre P. A., Browne M. A. (1995): The single cell gel electrophoresis assay for induced DNA damage (comet assay): measurement of tail length and moment. Mutagenesis 10, $85-90$ http://dx.doi.org/10.1093/mutage/10.2.85

Cheng D., Tung L., Sobie E. A. (1999): Nonuniform responses of transmembrane potential during electric field stimulation of single cardiac cells. Am. J. Physiol. Heart Circ. Physiol. 277, H351-362

Coleman M. L., Sahai E. A., Yeo M., Bosch M., Dewar A., Olson M. F. (2001): Membrane blebbing during apoptosis results from caspase-mediated activation of ROCK I. Nature Cell Biol. 3, 339-345 http://dx.doi.org/10.1038/35070009

Collins A. L. (2002): Comet assay - principles, applications, and limitations. Methods Mol. Biol. 203, 163-177

Daud A. I., Deconti R. C., Andrews S., Urbas P., Riker A. I., Sondak V. K., Munster P. N., Sullivan D. M., Ugen K. E., Messina J. L., Heller R. (2008): Phase I trial of interleukin-12 plasmid electroporation in patients with metastatic melanoma. J. Clin. Oncol. 26, 5896-5903

Deakin C. D., Nolan J. P. (2005): European resuscitation council guidelines for resuscitation 2005: Section 3. Electrical therapies: Automated external defibrillators, defibrillation, cardioversion and pacing. Resuscitation 67, S1, S25-37 http://dx.doi.org/10.1016/j.resuscitation.2005.10.008

Deakin C. D., Ambler J. J. (2006): Post-shock myocardial stunning: a prospective randomised double-blind comparison of monophasic and biphasic waveforms. Resuscitation 68, $329-333$

http://dx.doi.org/10.1016/j.resuscitation.2005.07.021

Deodhar A., Dickfeld T., Single G., Hamilton W., Thornton R., Sofocleous C., Maybody M., Gónen M., Rubinsky B., Solomon S. (2011): Irreversible electroporation near the heart: ventricular arrhythmias can be prevented with ECG synchronization. AJR Am. J. Roentgenol. 196, W330-335 http://dx.doi.org/10.2214/AJR.10.4490

Dosdall D. J., Fast V. G., Ideker R. E. (2010): Mechanisms of defibrillation. Annu Rev. Biomed. Eng. 12, 233-258 http://dx.doi.org/10.1146/annurev-bioeng-070909-105305

Dyachok O., Zhabyeyev P., McDonald T. F. (2010): Electroporation-induced inward current in voltage-clamped guinea pig ventricular myocytes. J. Membrane Biol. 238, 69-80 http://dx.doi.org/10.1007/s00232-010-9320-Z

Fedorov V. V., Nikolski V. P., Efimov I. R. (2008): Effect of electroporation on cardiac electrophysiology. Methods Mol. Biol. 423, 433-448 http://dx.doi.org/10.1007/978-1-59745-194-9_34

Klauke N., Smith G., Cooper J. M. (2010): Regional electroporation of single cardiac myocytes in a focused electric field. Anal. Chem. 82, 585-592 http://dx.doi.org/10.1021/ac901886j

Hescheler J., Meyer R., Plant S., Krautwurst D., Rosenthal W., Schultz G. (1991): Morphological, biochemical, and electrophysiological characterization of a clona cell (H9c2) line from rat heart. Circ. Res. 69, 1476-1486

Mali B., Jarm T., Corovic S., Paulin-Kosir M. S., Cemazar M., Sersa G., Miklavcic D. (2008): The effect of electroporation pulses on functioning of the heart. Med. Biol. Eng. Comput. 46, 745-757 http://dx.doi.org/10.1007/s11517-008-0346-7

Marty M., Serša G., Garbay J. R., Gehl J., Collins C. G., Snoj M., Billard V., Geertsen P. F., Larkin J. O., Miklavčič D., Pavlović I., Paulin-Košir S. M., Čemažar M., Morsli N., Soden D. M., Rudolf Z., Robert C., O’Sullivan G. C., Mir L. M. (2006): Electrochemotherapy - An easy, highly effective and safe treatment of cutaneous and subcutaneous metastases: Results of ESOPE (European Standard Operating Procedures of Electrochemotherapy) study. Eur. J. Cancer Suppl. 4, 3-13 http://dx.doi.org/10.1016/j.ejcsup.2006.08.002

Mir L. M. (2009): Nucleic acids electrotransfer-based gene therapy (electrogenetherapy): past, current, and future. Mol. Biotechnol. 43, $167-176$ http://dx.doi.org/10.1007/s12033-009-9192-6

Nelms B. E., Moravec R., Riss T. (1997): Measuring apoptosis in individual cells with the comet assay. Promega Notes 64, 13

Neumann E., Rosenheck K. (1972): Permeability changes induced by electric impulses in vesicular membranes. J. Membr. Biol. 10, 279-290 http://dx.doi.org/10.1007/BF01867861

Neumann E., Schaefer-Ridder M., Wang Y., Hofschneider P. H. (1982): Gene transfer into mouse lymphoma cells by electroporation in high electric fields. EMBO J. 1, 841-845 
Nikolski V. P., Efimov I. R. (2005): Electroporation of the heart. Europace 7, 146-154

http://dx.doi.org/10.1016/j.eupc.2005.04.011

de Oliveira P. X., Bassani R. A., Bassani J. W. M. (2008): Lethal effect of electric fields on isolated ventricular myocytes. IEEE Trans. Biomed. Eng. 55, 2635-2642

http://dx.doi.org/10.1109/TBME.2008.2001135

Roth B. J ., Krassowska W. (1998): The induction of reentry in cardiac tissue. The missing link: how electric fields alter transmembrane potential. Chaos 8, 204-220 http://dx.doi.org/10.1063/1.166298

Saczko J., Nowak M., Skolucka N., Kulbacka J., Kotulska M. (2010) The effects of the electro-photodynamic in vitro treatment on human lung adenocarcinoma cells. Bioelectrochemistry 79, 90-94

http://dx.doi.org/10.1016/j.bioelechem.2009.12.006
Skolucka N., Daczewska M., Saczko J., Chwilkowska A., Choromanska A., Kotulska M., Kaminska I., Kulbacka J. (2011): ETM study of electroporation influence on cell morphology in human malignant melanoma (Me-45) and human primary gingival fibroblast (HGFs) cells. Asian Pacific J. Trop. Biomed. 2, 1-5

Zareba W., Klein H., Cygankiewicz I., Hall J., McNitt S., Brown M., Cannom D., Daubert J., Eldar M., Gold M., Goldberger J., Goldenberg I., Lichstein E., Pitschner H, Rashtian M., Solomon S., Viskin S., Wang P., Moss A. (2011): Effectiveness of cardiac resynchronization therapy by qrs morphology in the multicenter automatic defibrillator implantation trial-cardiac resynchronization therapy (MADIT-CRT). Circulation 123, 1061-1072 http://dx.doi.org/10.1161/CIRCULATIONAHA.110.960898

Received: March 6, 2011

Final version accepted: September 6, 2011 